\title{
Treatment Patterns of Patients with All-Cause Dementia in Russia
}

\author{
Karel Kostev ${ }^{\mathrm{a}, *}$ and Galina Osina ${ }^{\mathrm{b}}$ \\ ${ }^{a}$ Epidemiology, IQVIA, Frankfurt, Germany \\ bIQVIA, Moscow, Russia
}

Accepted 3 January 2020

\begin{abstract}
.
Background: Studies on prevalence or the therapy of dementia are rare or non-existent in Russia.

Objective: The purpose of this study was to analyze the prescription patterns of antidementia therapy in Russia in 2018.

Methods: This retrospective cross-sectional study was based on the IQVIA Russia LRx database, which covers approximately $11 \%$ of all patients enrolled in federal or regional reimbursement state healthcare programs. We descriptively analyzed the proportions of patients treated with antidementia drugs, antipsychotics, antidepressants, and benzodiazepines.

Results: A total of 12,051 dementia patients were available for analysis. Of those, 6,394 patients had a vascular dementia (VaD) diagnosis, while 3,413 were diagnosed with dementia in other diseases (DOD), 1,128 with Alzheimer's disease (AD), and 1,116 with unspecified dementia (UD). The therapy with the highest patient proportion was antipsychotics, with $74 \%$ of VaD patients, 73\% of UD patients, and 47\% of DOD patients receiving these drugs. The proportion of patients treated with antidementia drugs was $68 \%$ in $\mathrm{AZ}, 56 \%$ in $\mathrm{VaD}, 45 \%$ in UD, and only 9\% in DOD. Antidepressants were a relatively rare therapy in dementia patients (between $4 \%$ and $12 \%$ ), and $30 \%$ of DOD patients received benzodiazepines, while the proportions of patients receiving this therapy class in other dementias was low (7-10\%). Most patients were treated with old-generation drugs.

Conclusion: The proportion of older drugs prescribed in Russia is higher than in Western Europe, which may likely be due to their low prices, resulting in a higher chance for successful health insurance reimbursement claims.
\end{abstract}

Keywords: Antidepressants, antipsychotics, benzodiazepine, dementia, Russia

\section{INTRODUCTION}

Dementia is a neuropsychiatric disorder caused by neurodegeneration that leads to a progressive loss of cognitive functions [1]. A recently published systematic review and meta-analysis reported the ageand sex-standardized prevalence rate of dementia in Europe to be $7.1 \%$ [2]. Russia is a country with about 145 million inhabitants, and about $12 \%$ of them are

\footnotetext{
${ }^{*}$ Correspondence to: Prof. Dr. rer. med. Karel Kostev, Epidemiology, IQVIA, Unterschweinstiege 2-14, 60549 Frankfurt am Main, Germany. Tel.: +49 (0)69 6604 4878; E-mail: kkostev@de.imshealth.com.
}

65 or older [3]. In 2010, Russia was estimated to be among the nine countries with the highest number of people with dementia $[4,5]$.

Therapy patterns of dementia patients constitute an important research subject, and in recent years, several studies focusing on this issue have been published in different countries throughout the world [6-12]. Russia has essentially not yet been covered by research, and studies on prevalence or the therapy of chronic diseases like dementia are rare or non-existent.

Therefore, the goal of this retrospective study was to analyze the prescription patterns of antidementia therapy in Russia in 2018. 
Table 1

Basic characteristics of dementia patients in this study

\begin{tabular}{lcccc}
\hline Variable & $\begin{array}{c}\text { Vascular } \\
\text { dementia } \\
\text { (ICD- 10: F01) }\end{array}$ & $\begin{array}{c}\text { Dementia in } \\
\text { other diseases } \\
\text { classified } \\
\text { elsewhere } \\
\text { (ICD- 10: F02) }\end{array}$ & $\begin{array}{c}\text { Alzheimer's } \\
\text { disease } \\
\text { (ICD-10: G30) }\end{array}$ & $\begin{array}{c}\text { Unspecified } \\
\text { dementia } \\
\text { (ICD-10: F03) }\end{array}$ \\
\hline $\mathrm{N}$ & 6,394 & 3,413 & 1,128 & \\
Age (Mean, SD) & $74.6(13.1)$ & $53.2(18.7)$ & $67.2(17.4)$ & $70.2(17.7)$ \\
Male & 40.8 & 53.0 & 37.2 & 31.7 \\
Female & 59.2 & 47.0 & 62.8 & 68.3 \\
Treating physician & & & & \\
$\quad$ Neuropsychiatrist & 93.0 & 84.0 & 68.5 & 93.1 \\
$\quad$ General practitioner & 4.1 & 6.7 & 24.2 & 3.9 \\
$\quad$ Others & 2.9 & 9.3 & 7.3 & 3.0 \\
Category of disability & & & & \\
$\quad$ I (mild) & 40.1 & 11.4 & 28.3 & 43.9 \\
$\quad$ II (moderate) & 45.7 & 47.5 & 46.3 & 44.1 \\
$\quad$ III (severe) & 14.2 & 41.1 & 25.4 & 12.0 \\
\hline
\end{tabular}

\section{METHODS}

This retrospective cross-sectional study was based on the IQVIA Russia LRx database, which covers approximately $11 \%$ of all patients enrolled in federal or regional reimbursement state healthcare programs. The data is properly anonymized (in accordance with Federal Law 152, which is similar to the EU General Data Protection Regulation) and allows for longitudinal tracking of each patient via a unique patient ID. Other data attributes include age, sex, diagnosis, and prescription information (therapy with the indication of trade name, molecule, drug form, dosage, manufacturer, region in which the drug was dispensed, prescription period), and prescriber specialty.

Outpatients with dementia, including vascular dementia (VaD) (ICD-10: F01), dementia in other diseases (DOD) (ICD-10: F02), Alzheimer's disease (AD) (ICD-10: G30), and unspecified dementia (UD) (ICD-10: F03), who received prescriptions in the time period between January 2018 and December 2018 , were included in our analyses. We analyzed the following therapy classes (based on the anatomical classification of pharmaceutical products published by the European Pharmaceutical Market Research Association (EphMRA)): antidementia drugs (ATC: N07D), antipsychotics (ATC: M05A), antidepressants (ATC: N06A), and benzodiazepines (N05 C).

We separately analyzed the proportions of dementia patients treated with each of four antidementia drugs: donepezil, galantamine, memantine, and rivastigmine, as well as the proportions of patients treated with several antipsychotics, antidepressants, and benzodiazepines.
This study is of a descriptive nature, and no hypotheses were tested. All analyses were carried out using SAS version 9.4.

\section{RESULTS}

In total, 12,051 dementia patients who were seen by 1,325 physicians and received medication therapy were available for analysis. Of those, 6,394 patients had a VaD diagnosis, while 3,413 were diagnosed with DOD, 1,128 with AD, and 1,116 with UD. The mean age varied between 53.2 years in DOD and 74.6 years in $\mathrm{VaD}$ patients. The proportion of females was highest in the UD group (68.3\%) and lowest in the DOD group (47.0\%). The majority of patients were treated by neuropsychiatrists (Table 1 ).

The proportion of defined therapy classes in dementia patients is shown in Figure 1. The therapy with the highest patient proportion was antipsychotics, with $74 \%$ of $\mathrm{VaD}$ patients, $73 \%$ of UD patients, and $47 \%$ of DOD patients receiving these drugs. The proportion of patients treated with antidementia drugs was $68 \%$ in $\mathrm{AZ}, 56 \%$ in $\mathrm{VaD}, 45 \%$ in UD, and only $9 \%$ in DOD. Antidepressants were a relatively rare therapy in dementia patients (between $4 \%$ and $12 \%$ ), and $30 \%$ of DOD patients received benzodiazepines, while the proportions of patients receiving this therapy class in other dementias was low (7\%-10\%).

Among patients treated with antidementia drugs, memantine had the highest shares (between $46 \%$ in $\mathrm{AD}$ patients and $62 \%$ in UD patients), followed by galantamine (from $21 \%$ in UD patients to $41 \%$ in 


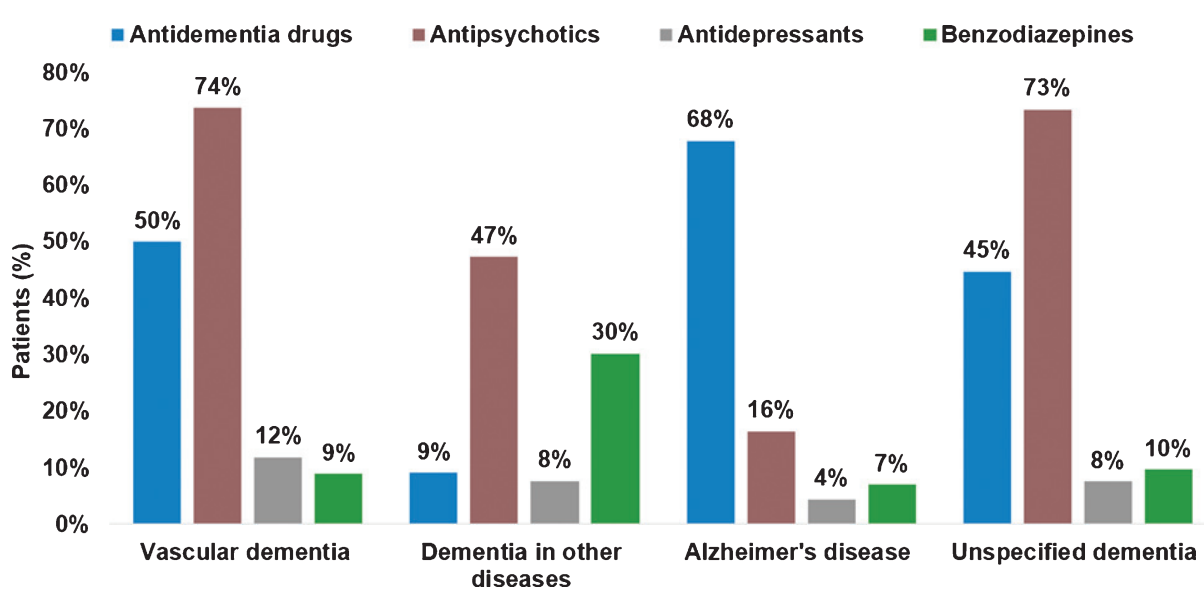

Fig. 1. Therapy classes prescribed to dementia patients in Russia in 2018.

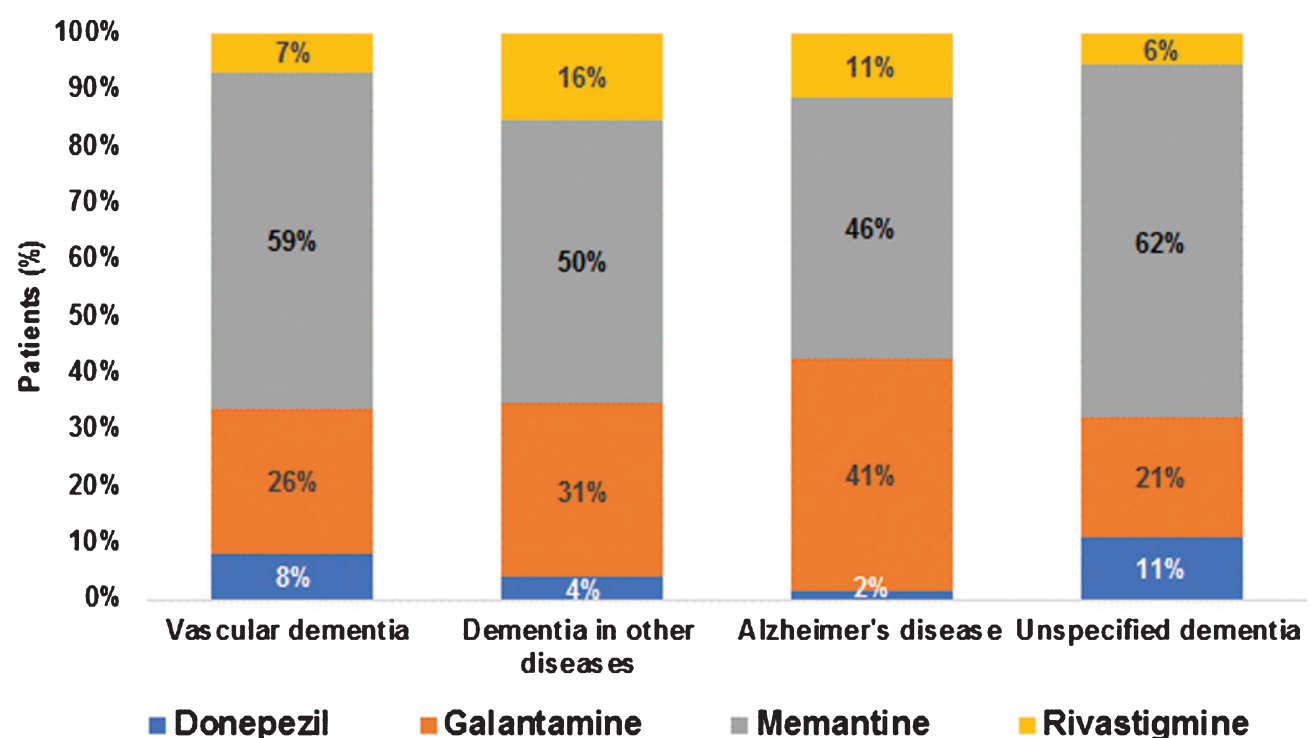

Fig. 2. Drugs prescribed to dementia patients in Russia in 2018.

$\mathrm{AD}$ patients). Both donepezil and rivastigmine were prescribed much less frequently (Fig. 2).

Antipsychotic therapy strongly differed between patients within the four dementia groups studied herein. In VaD patients, chlorprothixene (49\% of patients treated with antipsychotics), haloperidol (27\%), and quetiapine $(21 \%)$ were the three must frequently prescribed drugs. The same drugs were frequently given to UD patients (chlorprothixene $48 \%$, haloperidol $21 \%$, and quetiapine $20 \%$ ). In DOD patients, chlorpromazine $(36 \%)$ and thioridazine $(28 \%)$ were the most frequently prescribed, while in $\mathrm{AD}$ patients, quetiapine $(34 \%)$ and thioridazine $(23 \%)$ were prescribed more often.

About 20 different antidepressants were prescribed. Amitriptyline (28\%) and fluvoxamine (23\%) were the only drugs with a proportion of at least $20 \%$ in $\mathrm{VaD}$ patients, and paroxetine $(21 \%)$ and amitriptyline $(20 \%)$ the only ones with a proportion of at least $20 \%$ in UD patients. Amitriptyline was the only frequently prescribed antidepressant In DOD and AD patients (62\% in DOD, $36 \%$ in $\mathrm{AD}$ ).

Phenozepam was the only frequently used drug when dementia patients received benzodiazepines 
(83\% in $\mathrm{VaD}, 76 \%$ in $\mathrm{DOD}, 80 \%$ in $\mathrm{AD}$, and $86 \%$ in UD patients).

\section{DISCUSSION}

In this retrospective study of about 12,000 individuals with dementia, the treatment classes used differed between dementia types. Patients in Russia with dementia types that mainly occur in elderly patients (i.e., $\mathrm{VaD}$ and $\mathrm{AD}$ ) were relatively young (67 years in the $\mathrm{AD}$ and 75 years in the $\mathrm{VaD}$ group). For example, in Germany, the average age of dementia patients was 81 years $[13,14]$, while in Poland, the proportion of dementia patients aged $\geq 75$ years was about $76 \%$ [15]. The reason for this difference may be the relatively low life expectancy in Russia (65.5 years in men, 76.5 years in women), especially in non-central and rural regions $[3,16]$.

In Russia, $58 \%$ of $\mathrm{VaD}$ and $68 \%$ of $\mathrm{AD}$ patients received antidementia drugs. These shares were higher than in Germany (47\%) [17]. However, a valid comparison is not possible since all diagnosed dementia patients in Germany were used as denominator and, in Russia, dementia patents with at least one prescription for dementia were classified, resulting in the overestimation of the prevalence rates. A prevalence of dementia therapy of about $50 \%$ can be assumed, so the prevalence of antidementia drug use in dementia patients is about $30 \%$ and thus in line with the value reported by Vasenina et al. [18].

When discussing the possible reasons for the treatment behavior of non-university-based physicians in non-English-speaking countries, it is important to understand which sources these physicians use to be informed about evidence-based medicine studies. In Russia, the first line consists of Russian scientific journals. Publications on dementia are often published in the Zhurnal Nevrologii i Psikhiatrii imeni S.S. Korsakova.

Memantine is the most frequently prescribed antidementia drug in Russia. This drug was the subject of several studies published in Russian in this country, which have shown some therapy benefits for dementia patients [19-22]. The efficacy and safety of galantamine, which is frequently used in Russia, was also demonstrated [23-25].

In Russia, antipsychotics were often prescribed to dementia patients. This result is not surprising, as a similar situation was observed in Germany [26], where $47.7 \%$ of patients with dementia were treated with antipsychotics. Moreover, diagnosis of $\mathrm{VaD}$ was positively associated with therapy initiation. In line with the Germany study, the prevalence of antipsychotic use in Russia was highest in VaD patients. Explaining why antipsychotics like chlorprothixene, haloperidol, quetiapine, chlorpromazine, and thioridazine were more frequently prescribed than other drugs is difficult. Four of these drugs (chlorprothixene, haloperidol, chlorpromazine, and thioridazine) are old-generation antipsychotics that were introduced many decades ago and have low prices, thus gaining a higher share in the reimbursement segment. Studies from Russia on antipsychotic use in elderly patients are lacking, but several studies have been published in Europe and the U.S. For example, in a large retrospective study, the mortality risk in older adults was found to be increased for haloperidol and decreased for quetiapine and olanzapine [27]. Schmedt et al. reported a higher risk of death in patients treated with haloperidol, levomepromazine, and zuclopenthixol compared to risperidone. Lower risks were observed for quetiapine, prothipendyl, olanzapine, tiapride, clozapine, perazine, and flupentixol [28].

The proportion of benzodiazepine prescriptions in dementia patients in Russia was very similar to that in Germany (10\%) [29]. However, the prescribed drugs differ from country to country (phenazepam in Russia, diazepam in Germany). Phenazepam is a benzodiazepine developed about 50 years ago in the former USSR, and its toxicity is considered to be lower than that of other benzodiazepines. This drug has often been prescribed in Russia for anxiolytic, sedative-hypnotic, or anti-epileptic uses [30].

Amitriptyline was the antidepressant most frequently prescribed to antidementia patients in Russia. In a claims data analysis from Germany, amitriptyline was dispensed more often than other tricyclic antidepressants [31]. However, amitriptyline has been a potentially inappropriate medication for elderly patients for years and is included in international PRISCUS (Latin for "old and venerable") lists [32]. Again, amitriptyline is an old-generation antidepressant with a low price and a good chance in the reimbursement segment.

This study is the first using Russian data representing the therapy patterns of dementia patients. However, it is subject to several limitations that should be mentioned at this point. The first limitation is the short time period the investigation covers. A longer time period was not possible as LRx data in Russia are only available from 2018 onward. Second, the $11 \%$ coverage of the LRx database is relatively 
limited and does not include many regions. Third, the LRx database does not include any information on the reasons for the physicians' decisions in terms of antidementia drugs or antipsychotic prescriptions in dementia patients. Fourth, the database lacks information on the severity of the disease and additional disease details. For example, in DOD patients, no information was available on what the other diseases were (Parkinson's disease, epilepsy, multiple sclerosis, etc.). Fifth, no information about urban and rural areas was available, which could play an important role in the treatment of dementia. Nevertheless, the main strength of this study is that the LRx database contains real-world data and large patient numbers, which allowed for an estimation of the prevalence of antidementia prescriptions in Russia.

The drug classes prescribed to dementia outpatients in Russia do not considerably differ from those given in Europe. However, the proportion of older drugs in Russia is higher than in Western Europe; this finding is probably due to the low prices of older drugs, resulting in a higher chance for successful health insurance reimbursement claims.

\section{CONFLICT OF INTEREST}

The authors declare that they have no competing interests.

\section{REFERENCES}

[1] Sousa RM, Ferri CP, Acosta D, Albanese E, Guerra M, Huang Y, Jacob KS, Jotheeswaran AT, Rodriguez JJ, Pichardo GR, Rodriguez MC, Salas A, Sosa AL, Williams J, Zuniga T, Prince M (2009) Contribution of chronic diseases to disability in elderly people in countries with low and middle incomes: a 10/66 Dementia Research Group population-based survey. Lancet 374, 1821-1830.

[2] Bacigalupo I, Mayer F, Lacorte E, Di Pucchio A, Marzolini F, Canevelli M, Di Fiandra T, Vanacore N (2018) A systematic review and meta-analysis on the prevalence of dementia in Europe: estimates from the highest-quality studies adopting the DSM IV diagnostic criteria. J Alzheimers Dis 66, 1471-1481.

[3] Bucher S (2016) Ageing of the population in the Russian Federation: The current trends and indicators. Herald Russian Acad Sci 86, 97-104.

[4] Prince M, Bryce R, Albanese E, Wimo A, Ribeiro W, Ferri CP (2013) The global prevalence of dementia: a systematic review and metaanalysis. Alzheimers Dement 9, 63-75.e2.

[5] GBD 2016 Neurology Collaborators (2019) Global, regional, and national burden of neurological disorders, 1990-2016: A systematic analysis for the Global Burden of Disease Study 2016. Lancet Neurol 18, 459-480.

[6] Calvo-Torres LF, Bernal-Cobo R, Trujillo-Quintero PM, Gaviria-Mendoza A, Machado-Alba JE (2019) Patterns of antidemential drug use in a group of patients from Colombia. Rev Neurol 68, 409-416.

[7] Aigbogun MS, Stellhorn R, Hartry A, Baker RA, Fillit H (2019) Treatment patterns and burden of behavioral disturbances in patients with dementia in the United States: a claims database analysis. BMC Neurol 28, 33.

[8] Wübbeler M, Wucherer D, Hertel J, Michalowsky B, Heinrich S, Meyer S, Schaefer-Walkmann S, Hoffmann W, Thyrian JR (2015) Antidementia drug treatment in dementia networks in Germany: use rates and factors associated with treatment use. BMC Health Serv Res 22, 205.

[9] Wucherer D, Eichler T, Kilimann I, Hertel J, Michalowsky B, Thyrian JR, Teipel S, Hoffmann W (2015) Antidementia drug treatment in people screened positive for dementia in primary care. J Alzheimers Dis 44, 1015-1021.

[10] Michalowsky B, Kostev K, Iliffe S, Hoffmann W, Bohlken $\mathrm{J}$ (2018) Diagnosing and treating dementia in German primary and specialized care between 2011 and 2015. Int $J$ Clin Pharmacol Ther 56, 301-309.

[11] Jacob L, Bohlken J, Kostev K (2017) Prescription patterns and drug costs in German patients with dementia in nursing homes and home-care settings. Int J Clin Pharmacol Ther 55, 9-15.

[12] Bohlken J, Schulz M, Rapp MA, Bätzing-Feigenbaum J (2015) Pharmacotherapy of dementia in Germany: Results from a nationwide claims database. Eur Neuropsychopharmacol 25, 2333-2338.

[13] Bohlken J, Jacob L, Kostev K (2019) The relationship between the use of antihypertensive drugs and the Incidence of dementia in general practices in Germany. J Alzheimers Dis 70, 91-97.

[14] Jacob L, Bohlken J, Kostev K (2017) Prevalence of use of cardiovascular drugs in dementia patients treated in general practices in Germany. J Alzheimers Dis 56, 1519-1524.

[15] Kostev K, Kurylo P, Kosik J, Jacob L (2019) One-year persistence with donepezil, memantine, and rivastigmine in more than 66,000 elderly patients followed in Poland. $J$ Alzheimers Dis 70, 899-905.

[16] Timonin S, Danilova I, Andreev E, Shkolnikov VM (2017) Recent mortality trend reversal in Russia: are regions following the same tempo? Eur J Popul 33, 733-763.

[17] Bohlken J, Kostev K (2018) Diagnostic and prescription behavior of general practitioners and specialist physicians in patients with dementia in 2005 and 2015 in Germany. Psychiatr Prax 45, 154-159.

[18] Vasenina EE, Levin OS, Sonin AG (2017) Modern trends in epidemiology of dementia and management of patients with cognitive impairment. Zh Nevrol Psikhiatr Im S S Korsakova 117, 87-95.

[19] Levin O, Yunishchenko N, Dudarova M (2010) Efficacy of akatinol memantine in moderate cognitive impairments. Neurosci Behav Physiol 40, 926-933.

[20] Uspenskaya O, Yakhno N (2009) PO22-TH-04 Memantine hampers the progression of cognitive dysfunction and conversion to dementia in amnestic MCI patients. J Neurol Sci 285, 275.

[21] Yakchno NN, Preo-brazhenskayaI S, Zakharov VV, Mkhitaryan EA (2010) Efficacy of akatinol memantine in patients with non-dementia cognitive impairments. Results of multicenter study. J Nerv Dis 15, 52-58.

[22] Bolshakov YuA, Merkel VA, Solovyova NV (2019) Acatinol (memantine) in the in-patient treatment of moderate and severe dementia. Soc Clin Psychiatry 19, 61-64.

[23] Litvinenko IV, Odinak MM, Mogil'naia VI, Emelin AIu (2007) Efficacy and safety of galantamine (reminyl) in the 
treatment of dementia in patients with Parkinson's disease (open-label controlled trial)]. Zh Nevrol Psikhiatr Im S S Korsakova 107, 25-33.

[24] Voronkova KV, Pylaeva OA, Mazal'skaia OV, Lemeshko ID, Petrukhin AS (2006) Use of reminyl (galantamine) in the treatment of dementia. Zh Nevrol Psikhiatr Im S S Korsakova 106, 26-30.

[25] Zhivolupov SA, Rashidov NA, Samartsev IN, Jakovlev EV (2015) A comparative analysis of the efficacy of neuromidin and galantamine in Alzheimer's disease]. Zh Nevrol Psikhiatr Im S S Korsakova 115, 22-27.

[26] Bohlken J, Booker A, Kostev K (2017) High prevalence of antipsychotic medication use in dementia patients in German neuropsychiatric practices. Fortschr Neurol Psychiatr $\mathbf{8 5}, 345-351$

[27] Gerhard T, Huybrechts K, Olfson M, Schneeweiss S, Bobo WV, Doraiswamy PM, Devanand DP, Lucas JA, Huang C, Malka ES, Levin R, Crystal S (2014) Comparative mortality risks of antipsychotic medications in community-dwelling older adults. Br J Psychiatry 205, 44-51.
[28] Schmedt N, Kollhorst B, Enders D, Jobski K, Krappweis J, Garbe E, Schink T (2016) Comparative risk of death in older adults treated with antipsychotics: a population-based cohort study. Eur Neuropsychopharmacol 26, 1390-1400.

[29] Mell T, Jacob L, Fuhr I, Dick S, Rapp MA, Kostev K (2017) Patterns of benzodiazepine prescribing by neuropsychiatrists and general practitioners for elderly patients in Germany in 2014. Int J Clin Pharmacol Ther 55, 466-471.

[30] Kriikku P, Wilhelm L, Rintatalo J, Hurme J, Kramer J, Ojanperä I (2012) Phenazepam abuse in Finland: findings from apprehended drivers, post-mortem cases and police confiscations. Forensic Sci Int 10, 111-117.

[31] Hessmann P, Zeidler J, Stahmeyer J, Eberhard S, Vogelgsang J, Abdel-Hamid M, Wolff-Menzler C, Wiltfang J, Kis B (2019) Claims data analysis on the dispensing of tricyclic antidepressants among patients with dementia in Germany. Front Pharmacol 24, 841.

[32] Holt S, Schmiedl S, Thürmann PA (2010) Potentially inappropriate medications in the elderly: the PRISCUS list. Dtsch Arztebl Int 107, 543-551. 